Bentham OPen The Open Civil Engineering Journal

RESEARCH ARTICLE

\title{
Creation of Similarity Requirement with Field Equations in Steel Bearing Systems
}

\author{
Ahmet C. Altunışık ${ }^{*}$ Ebru Kalkan and Hasan Basri Başağa \\ Department of Civil Engineering, Karadeniz Technical University, Trabzon, Turkey
}

Received: April 9, 2018

Revised: May 5, 2018

Accepted: May 29, 2018

\begin{abstract}
:
Introduction:

This paper aimed to determine the structural behavior of steel bearing systems by creating similarity conditions with field equations. Scaling plays a crucial role in designing experiments aimed at understanding the structural behavior of systems where experimental studies are difficult to perform due to huge structures in the profession of engineering field. Scaling can be performed by using dimensional analysis or by normalizing differential equations that describe the dynamics of the system. If a model and prototype are dimensionally similar, it is possible to estimate experimental results from model to prototype.
\end{abstract}

\section{Methods:}

The use of scaled models is common on engineering applications because these models allow conducting experimental tests without the need of a physical system (i.e. prototype) to be constructed. Considering these advantages mentioned in this study, it is formed a similarity relation between prototype and scaled models of different steel bearing systems is established. Similarity relationships between systems are created by field equations. As an example, column and cantilever beams were selected and 1/2 and 1/4 scale procedure was applied.

\section{Results and Conclusion:}

The results obtained by finite element models in SAP2000 program for each system were compared with analytical results. The analysis results were examined and it was determined that scale factors are constant depending on scale types for different bearing systems. In addition, the influence diagrams of the systems were also examined and it was observed that the scale factor was fixed.

Keywords: Dimensional analysis, Prototype, Scaled model, Similarity condition, Steel bearing system.

\section{INTRODUCTION}

Full-scale constructions have been designed and built on a small-scale in order to carry out experimental studies of the structures. Zhou et al. [1] have conducted experimental studies by producing scaled models in order to investigate the cracks that occur due to earthquake motions in the arch dam designed the earthquake acceleration which the possibility of which is expected to increase by $10 \%$ in the coming 500 years. Jiang and Shu [2] investigated on the effects of gun voices around the military area. For this purpose, using scaled models created in the laboratory environment with different acceleration records on the shake table, they examined the changes in dynamic characteristics. Oliveira and Faria [3] aimed to determine damage levels for arch dams in a study conducted using small scaled models. To this end, they built the 1/250 scaled models of the Alqueva and Alto Lindoso Arch Dam of 96 and $110 \mathrm{~m}$ height, respectively in the laboratory. To study the earthquake behavior of a dam with an arch height of $278 \mathrm{~m}$ and a crest length of $612.5 \mathrm{~m}$ in China, a $1 / 300$ scaled model of the dam was constructed in the laboratory environment,

* Address correspondence to this author at the Department of Civil Engineering, Karadeniz Technical University, Trabzon, Turkey; Tel: +90 (462) 3774020, Fax: +90 (462) 3774020; E-mails: ahmetcan8284@hotmail.com, ahmetcan@ktu.edu.tr 
including reservoir-ground interaction by Wang and $\mathrm{Li}$ [4]. Wang and He [5] investigated the effects of cracks occurring in arch dams with natural frequencies along with experimental studies conducted on large scaled models. In the scope of the study, a single curved arch dam was designed at an arch height of $80 \mathrm{~m}$ and crest length of $209 \mathrm{~m}$. Wang and $\mathrm{Li}$ [6] constructed the laboratory model of the dam by considering the dam-foundation-reservoir interaction in order to experimentally study the earthquake behavior of Xiao Wan Arch Dam which has the $292 \mathrm{~m}$ height in China. There are many experimental studies using scaled models in laboratory environment [7 - 11].

Dimensional analysis is used to determine the relationship between the prototype and the scaled model. Buckingham Pi Theorem is often used in many theoretical studies to determine this relationship. Carpinteri and Corrado [12] investigated structural behaviors such as cracking or fracture of concrete and yielding or rupture of reinforced during the loading process in reinforced concrete and yielding or rupture during the loading process in reinforced concrete beams subjected to bending effect by means of dimensional analysis. Ramu et al. [13] aimed to improve the rules of scaling with respect to Buckingham $\Pi$ Theorem and the similarity criteria. In the study, it is stated that scaled models similar to prototype can be created and uploaded. Balaguer and Claramonte [14], in the work presented, investigated importance, advantages and the goals of dimensional analysis in detail. It is correlated in between prototype and scaled models that created with Buckingham Pi Theorem. Ghosh [15] has dwelled on areas of usage of scaled models and has stated general descriptions. Balawi et al. [16] aimed at examining the scaling rules based on the theory of similarity in plates and beams under low velocity impact and static loading. In this study, in order to ensure compliance with prototypes, the scaled factor is presented as the ratio of each change in the scaled models. With established similarities between systems, it is stated that various equations written for a system apply to all systems, and that in many cases it is impossible to establish complete similarity between model and prototype.

Steel bearing system is studied by taking the scaling principles into consideration. In the scope of the study, $1 / 2$ and $1 / 4$ scaled models of steel column and console prototypes were created. Dynamic characteristics and structural behavior between prototypes and models were investigated.

\section{SCALING, SIMILARITY AND DIMENSIONAL ANALYSIS}

Scaling is the size reduction of large elements or systems and the size of small elements or systems by expanding them in a certain ratio. The aim of the scaling is to facilitate the work by making the hard and time-consuming systems smaller and simpler to test. Examining and testing of large structures (prototype) as multi-story buildings, dams and airports is a very expensive, time-consuming and difficult-to-control process. For this reason, it is very easy and convenient to do the study on the small models created by scaling the prototype. Owing to the similarity between the prototype and the model, the results obtained from the small model will be evaluated so that the behavior of the prototype can be predicted. The aim of similarity analysis is to reveal the relation between large and expensive systems by using information obtained from experiments of small models. There are some similarity laws that are used to accomplish this. Equality or relativity of variables written for a system is valid for all systems. Each variable in a model is proportional to the corresponding variable in the prototype.

Analytical and experimental studies are carried out to solve a problem. The solution of the problem is investigated firstly analytically. Then experimental measurements are made to check the accuracy of the results. The most suitable scales are used according to the dimensions of the systems in laboratory studies. There are two ways to relate the prototype with the scaled model. Similarity conditions, if there is a mathematical model of the system, are derived from the related field equations, or if the mathematical model of system is not valid, by means of dimensional analysis. In dimensional analysis, all parameters and variables that affect the behavior of the system have to be known. The equation created by dimensional analysis is the dimensionless product of system parameters and variables. Thus the similarity condition can be created by the obtained equation. Experimental studies, which are an important step in comparing and confirming correctness of results, require careful examination of experimental data. The main purpose of experimental studies is to obtain maximum information with the least experimentation. In line with this purpose, dimensional analysis is used. Dimensional analysis is a method used to reduce the number and complexity of experimental variables affecting a physical phenomenon considered.

The generalization of empirical formulas and diagrams obtained from experimental studies is very important in terms of applications in which the system with different dimensions is used. One of the main purposes of dimensional analysis is to establish experimental studies that will provide this generalization. In an experimental study, there may be dimensionless quantities that define the relationship between a large number of parameters affecting a studying. For this purpose, dimensional analysis is a method which has an effect on the interpretation of results with fewer parameters, 
and also provides ease of operation.

\subsection{Creation a Similarity Formula With the Aid of Mathematical Models}

With the field equations of the bearing systems, the characteristic properties and structural behaviors of the systems can be calculated. The frequency of systems varies in proportion to the stiffness. The stiffness values of some bearing systems are given in Table $\mathbf{1}$.

Table 1. Stiffness expressions of some bearing systems.

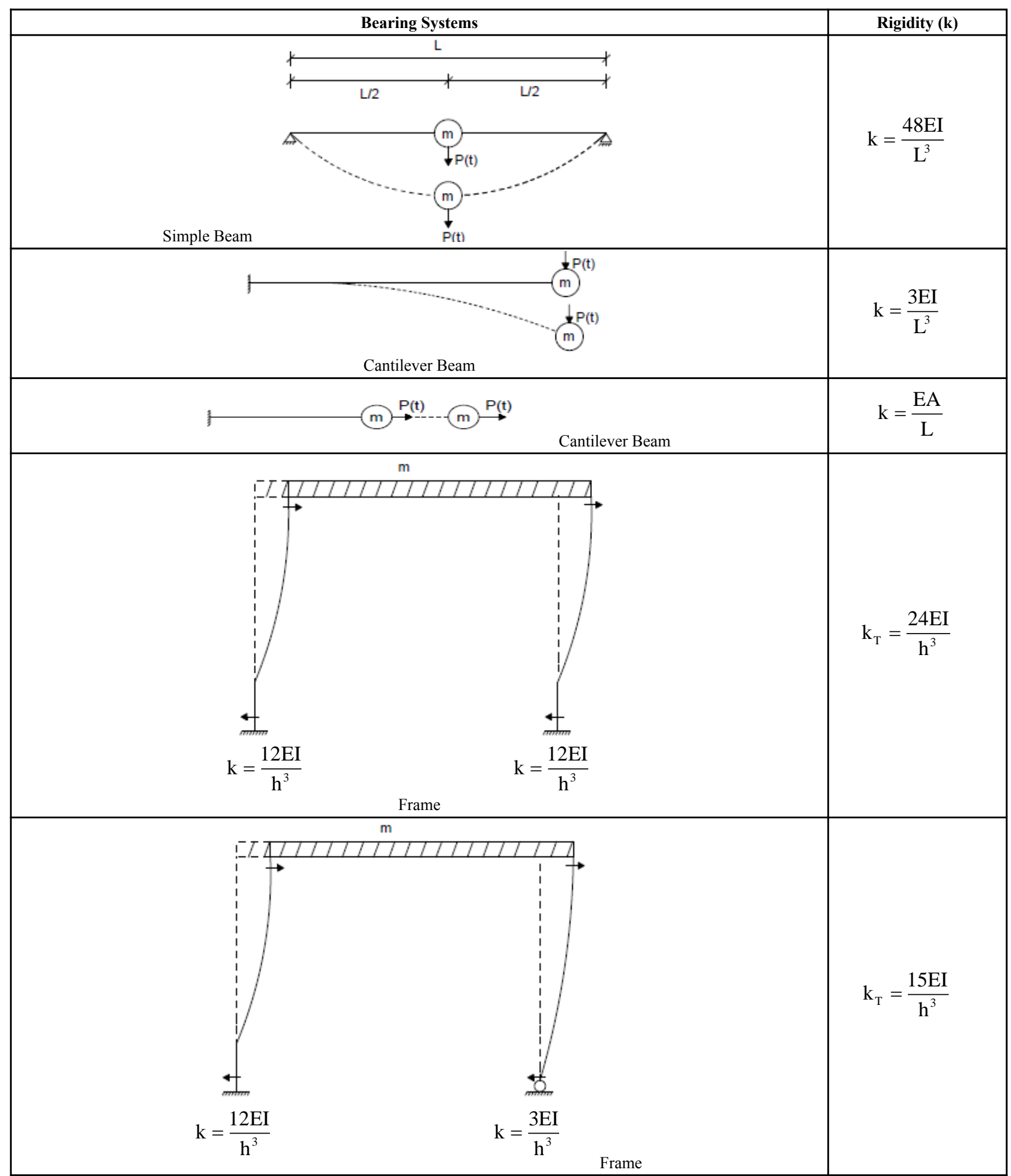

Where, I and EI are Moment of Inertia and flexural rigidity, respectively. 
The displacement relationships, which are an expression of the structural behavior of the system, are given in Table 2 for some carrier systems.

Table 2. Displacement expressions of some bearing systems.

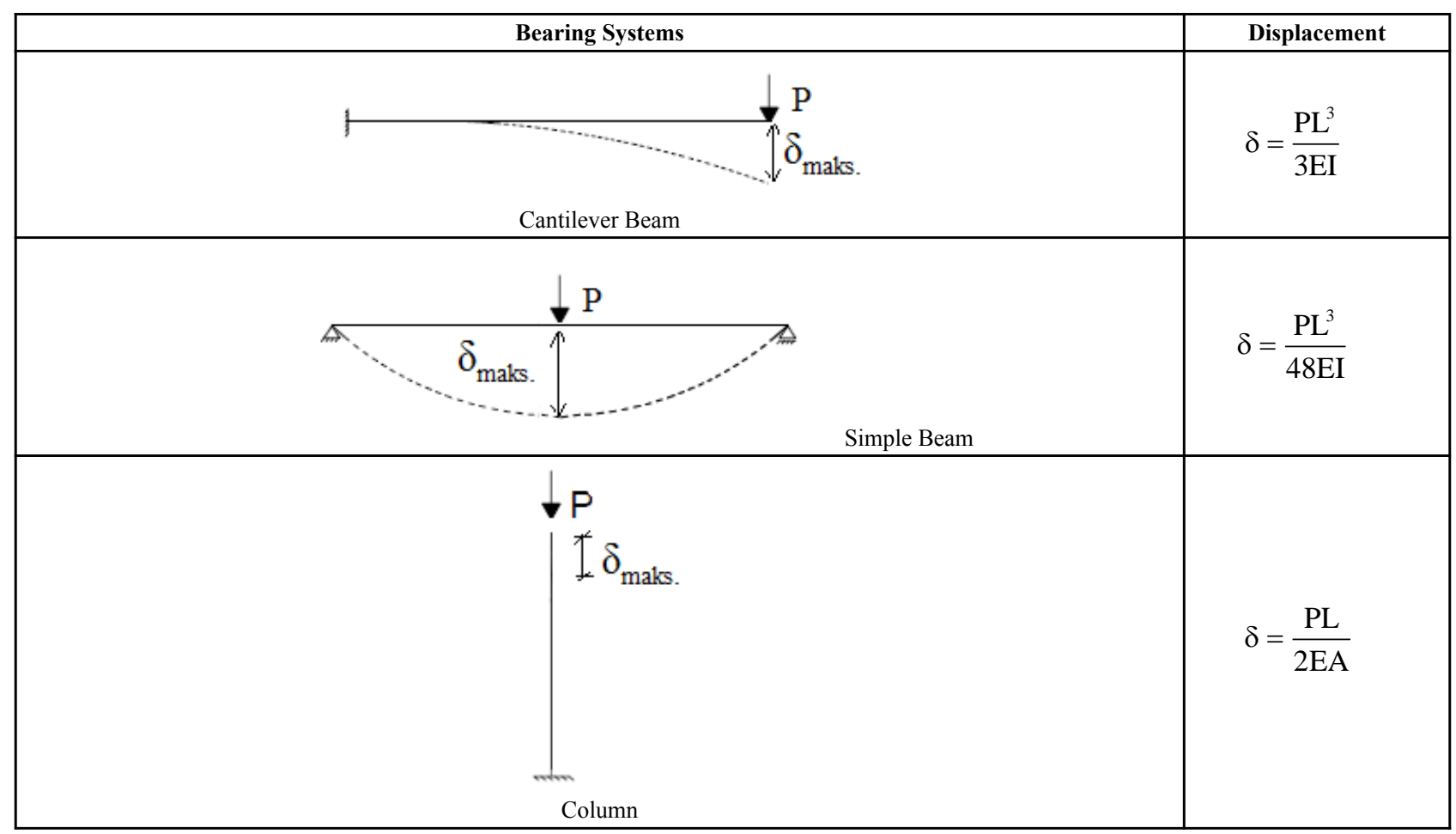

In the study carried out on the steel bearing systems, the sizes available in the steel tables are used because each dimension of the steel profiles cannot be scaled in the desired area. A geometric and mass scaled is applied as scaling type.

Frequency equations for bearing systems;

For symmetrical profiles

$$
\mathrm{k}=\frac{\mathrm{ZEI}}{\mathrm{L}^{3}}, \omega=\sqrt{\frac{\mathrm{k}}{\mathrm{m}}}, \mathrm{f}=\frac{\omega}{2 \pi}
$$

For non-symmetrical profiles

$$
\left.\begin{array}{l}
\mathrm{k}_{\mathrm{x}}=\frac{\mathrm{ZEI}_{\mathrm{y}}}{\mathrm{L}^{3}}, \omega_{\mathrm{x}}=\sqrt{\frac{\mathrm{k}_{\mathrm{x}}}{\mathrm{m}}}, \mathrm{f}_{\mathrm{x}}=\frac{\omega_{\mathrm{x}}}{2 \pi} \\
\mathrm{k}_{\mathrm{y}}=\frac{\mathrm{ZEI}_{\mathrm{x}}}{\mathrm{L}^{3}}, \omega_{\mathrm{y}}=\sqrt{\frac{\mathrm{k}_{\mathrm{y}}}{\mathrm{m}}}, \mathrm{f}_{\mathrm{y}}=\frac{\omega_{\mathrm{y}}}{2 \pi}
\end{array}\right\}
$$

are expressed (Eqs. 1-2). Where, Z, E, I, L, m and x-y are a coefficient, Modulus of Elasticity, the moment of inertia, the profile length, mass and the axis directions of the system, respectively. When these expressions are written in the frequency equation for prototype and model,

for prototype;

$$
\mathrm{f}_{\mathrm{p}}=\sqrt{\frac{\mathrm{ZEI}_{\mathrm{p}}}{\mathrm{L}_{\mathrm{p}}^{3}} \frac{1}{\mathrm{~m}_{\mathrm{p}}}} \frac{1}{2 \pi}
$$

for model; 


$$
\mathrm{f}_{\mathrm{m}}=\sqrt{\frac{\mathrm{ZEI}_{\mathrm{m}}}{\mathrm{L}_{\mathrm{m}}^{3}} \frac{1}{\mathrm{~m}_{\mathrm{m}}}} \frac{1}{2 \pi}
$$

Eqs. (3-4) are obtained. With the application of the similarity condition between prototype and model frequency equations,

$$
\left.\begin{array}{l}
\frac{f_{m}}{f_{p}}=\sqrt{\frac{Z E I_{m}}{L_{m}^{3}} \frac{1}{m_{m}} \frac{L_{p}^{3}}{Z E I_{p}} m_{p}} \frac{1}{2 \pi} \\
f_{m}=\sqrt{\frac{I_{m}}{I_{p}}} \sqrt{\left(\frac{L_{p}}{L_{m}}\right)^{3}} \sqrt{\frac{m_{p}}{m_{m}}} f_{p}
\end{array}\right\}
$$

Eq. (5) is obtained. Assuming that the mass is kept constant, the relation is $\mathrm{m}_{\mathrm{p}}=\mathrm{m}_{\mathrm{m}}$,

$$
f_{m}=\sqrt{\frac{I_{m}}{I_{p}}} \sqrt{\left(\frac{L_{p}}{L_{m}}\right)^{3}} f_{p}
$$

Eq. (6) is obtained.

For displacement equations;

$$
\begin{aligned}
\mathrm{F} & =\mathrm{K} \cdot \mathrm{U} \\
\mathrm{F} & =\mathrm{V} \cdot \gamma \\
\mathrm{k} & =\frac{\mathrm{ZEI}}{\mathrm{L}^{3}}
\end{aligned}
$$

Eq. (7) is obtained. Where, U, F, K, V, E, I, Z and L are displacement, force (mass of system), rigidity, volume, density, Modulus of Elasticity, Moment of Inertia, a coefficient and length, respectively.

For prototype:

$$
\mathrm{W}_{\mathrm{p}}=\frac{12 \mathrm{E}_{\mathrm{p}} \mathrm{I}_{\mathrm{p}}}{\mathrm{L}_{\mathrm{p}}^{3}} \mathrm{U}_{\mathrm{p}}
$$

For model:

$$
\mathrm{W}_{\mathrm{m}}=\frac{12 \mathrm{E}_{\mathrm{m}} \mathrm{I}_{\mathrm{m}}}{\mathrm{L}_{\mathrm{m}}^{3}} \mathrm{U}_{\mathrm{m}}
$$

(Eqs. 8-9) is obtained. With the application of the similarity condition $\frac{\mathrm{U}_{\mathrm{p}}}{\mathrm{U}_{\mathrm{m}}}$ between prototype and model,

Eq. (10) is obtained. With the application of the scale factor $\frac{\mathrm{L}_{\mathrm{m}}}{\mathrm{L}_{\mathrm{p}}}=\frac{1}{\mathrm{~S}}$ in Eq. (10)

$$
\frac{U_{p}}{U_{m}}=\frac{I_{m} W_{p}}{I_{p} W_{m}} S^{3}
$$

Eq. (11) is obtained. Assuming that the mass is kept constant, the relation is $\mathrm{m}_{\mathrm{p}}=\mathrm{m}_{\mathrm{m}}$,

$$
\frac{\mathrm{U}_{\mathrm{p}}}{\mathrm{U}_{\mathrm{m}}}=\frac{\mathrm{I}_{\mathrm{m}}}{\mathrm{I}_{\mathrm{p}}} \mathrm{S}^{3}
$$


Eq. (12) is obtained.

With the necessary simplifications, equations of frequency and displacement shows the most general situation. These generalized equations that reflect the relationship between prototype and model are applied to different systems.

\section{OBTAINING OF DYNAMIC CHARACTERISTICS AND STRUCTURAL BEHAVIOR}

\subsection{Finite Element Analysis}

Column and cantilever beams are selected for application of the scale effect in steel bearing systems. The fact that profiles are factory-made disallows them from being reduced in terms of size in all dimensions of system in case of scaling. For this reason, the dimensions in the steel tables are selected and processed. In the studies done in box and I profiles, 1/2 and 1/4 scaled models have been used. The properties of I profiles are presented in Table 3.

Table 3. Data for I profiles.

\begin{tabular}{|c|c|c|c|c|c|}
\hline \multicolumn{2}{|c|}{ I Profiles } & \multirow{2}{*}{ Weight (kN) } & \multirow{2}{*}{ Mass $\left(\mathbf{k N s} \mathbf{s}^{2} / \mathbf{m}\right)$} & \multicolumn{2}{c|}{ Moment of Inertia $\left(\mathbf{m}^{\mathbf{4}}\right)$} \\
\cline { 5 - 6 } & & & $\mathbf{I}_{\mathbf{X}}$ & $\mathbf{I}_{\mathbf{Y}}$ \\
\hline Dimension $(\mathbf{m m})$ & Length $(\mathbf{m})$ & & 0.1325459327 & $1.318 \mathrm{E}-6$ & $2.313 \mathrm{E}-4$ \\
\hline IPE400 & 2 & 1.3002756 & 0.0223986646 & $1.420 \mathrm{E}-6$ & $1.943 \mathrm{E}-6$ \\
\hline IPE200 & 1 & 0.2196544 & 0.0040483486 & $1.59 \mathrm{E}-7$ & $1.71 \mathrm{E}-6$ \\
\hline IPE100 & 0.5 & 0.0397143 &
\end{tabular}

The unit length weights $(\mathrm{G}, \mathrm{kg} / \mathrm{m})$ for I profiles are given in the steel tables. The weight of the selected profile is calculated by unit height. Since the weights of the unit height of the selected box profiles are not included in the tables, the weights of the selected profiles are calculated from specific formulas.

Unit length weights for box profile $(\mathrm{kg} / \mathrm{m})$;

$$
\mathrm{Kg} / \mathrm{m}=\left(\mathrm{O}_{\mathrm{c}}-4 \mathrm{~W}_{\mathrm{t}}\right) * \mathrm{~W}_{\mathrm{t}} * 0.00785
$$

calculated using Eq. (13) [17]. Where, $\mathrm{O}_{\mathrm{c}}$ and $\mathrm{W}_{\mathrm{t}}$ are outer diameter and wall thickness, respectively (Fig. 1).

for square section: $\mathrm{o}_{\mathrm{c}}=4 \mathrm{a}$

for rectangular section: $\mathrm{o}_{\mathrm{c}}=2 \mathrm{a}+2 \mathrm{~b}$

is obtained.
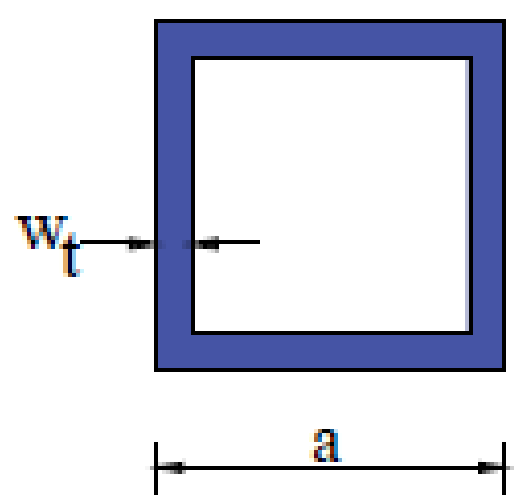
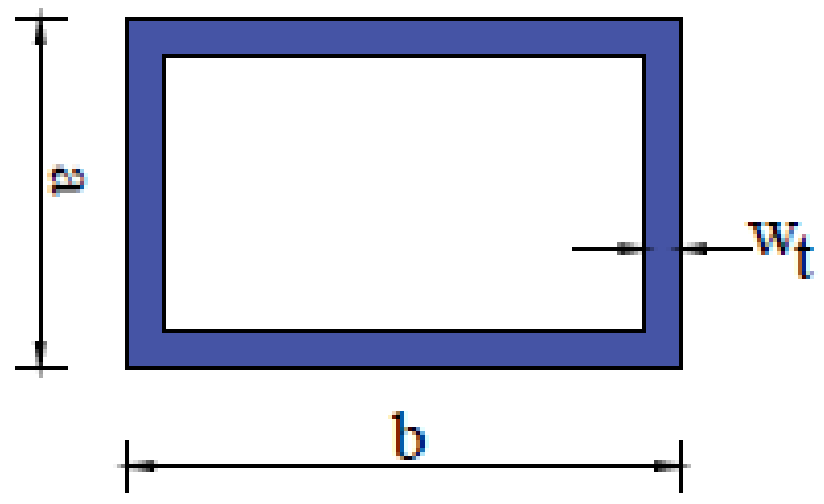

Fig. (1). Square and rectangular box sections.

400x400x8 mm unit weight of box profile;

$$
\begin{aligned}
& \mathrm{Kg} / \mathrm{m}=\left(\mathrm{O}_{\mathrm{c}}-4 \mathrm{~W}_{\mathrm{t}}\right) * \mathrm{~W}_{\mathrm{t}} * 0.00785 \\
& \mathrm{Kg} / \mathrm{m}=(4 * 400-4 * 8) * 8 * 0.00785 \\
& \mathrm{Kg} / \mathrm{m}=98.4704 \mathrm{~kg} / \mathrm{m}
\end{aligned}
$$


Eq. (14) is solved. $2 \mathrm{~m}$ long box profile weight,

$$
\begin{aligned}
& \mathrm{W}=98.47042 * 2=196.94084 \mathrm{~kg} \\
& \mathrm{~W}=196.94084 * 9.806 \mathrm{E}-3 \\
& \mathrm{~W}=1.931201877 \mathrm{kN}
\end{aligned}
$$

was calculated by (Eq. 15). By dividing the weight of the profile into gravity acceleration,

$$
\mathrm{m}=\frac{1.931201877}{9.81}=0.1968605379 \mathrm{kNs}^{2} / \mathrm{m}
$$

Eq. (16) was calculated. The masses of the other box profiles were calculated and presented in Table 4.

Table 4. Data for box profiles.

\begin{tabular}{|c|c|c|c|c|c|}
\hline \multicolumn{2}{|c|}{ Box Profiles } & \multirow{2}{*}{ Weight (kN) } & \multirow{2}{*}{ Mass (kNs $\left.{ }^{2} / \mathbf{m}\right)$} & \multicolumn{2}{c|}{ Moment of Inertia $\left(\mathbf{m}^{4}\right)$} \\
\cline { 1 - 2 } Dimension (mm) & Length (m) & & 0.1968605379 & $3.214 \mathrm{E}-4$ & $400 \times 400 \times 8$ \\
\hline $400 \times 400 \times 8$ & 2 & 1.931201877 & 0.02460756224 & $2.009 \mathrm{E}-5$ & $200 \times 200 \times 4$ \\
\hline $200 \times 200 \times 4$ & 1 & 0.2414001856 & 0.00307594528 & $1.255 \mathrm{E}-6$ & $100 \times 100 \times 2$ \\
\hline $100 \times 100 \times 2$ & 0.5 & 0.0301750232 & 0 \\
\hline
\end{tabular}

The finite element models of the selected profiles were created with the Sap2000 [18] program. The finite element models for the systems are shown in Fig. (2).

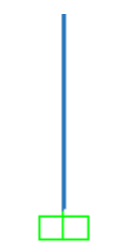

a) Box column

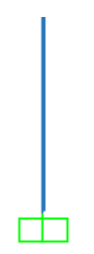

d) IPN column

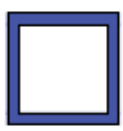

b) Box cantilever beam
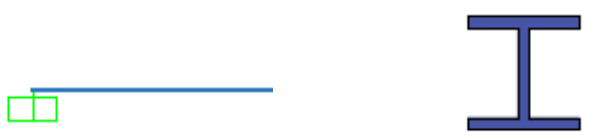

e) IPN cantilever beam

Fig. (2). Finite element models of steel profiles.

\subsection{Mathematical Model}

Frequency and displacement values were obtained analytically by using mathematical models of systems. The steps of calculation of the frequency value obtained as a result of considering the prototype, 1/2 and 1/4 scaled model of the column that is box profile are presented as follows:

The prototype Data of the Column

Dimensions $400 \times 400 \times 8 \mathrm{~mm}$

E $2.1 \mathrm{E} 8 \mathrm{KN} / \mathrm{m}^{2}$

I $3.214 \mathrm{E}-4 \mathrm{~m}^{4}$ 
$\mathrm{L} 2 \mathrm{~m}$

The solution steps taken considering the above mentioned data are as follows. With the help of equation;

$$
\begin{aligned}
& \mathrm{k}=\frac{12 * 1.2 \mathrm{E} 8 * 3.214 \mathrm{E}-4}{2^{3}}=101241 \mathrm{kN} / \mathrm{m} \\
& \omega=\sqrt{\frac{101241}{0.1968605379}}=717.1316322 \mathrm{rad} / \mathrm{s} \\
& \mathrm{f}_{\mathrm{p}}=\frac{717,1316322}{2 \pi}=114.1350441 \mathrm{~Hz}
\end{aligned}
$$

Eq. (17) was solved.

1/2 Scaled Model Data of the Column

Dimensions $200 \times 200 \times 4 \mathrm{~mm}$

$\mathrm{E} 2.1 \mathrm{E} 8 \mathrm{KN} / \mathrm{m}^{2}$

I $2.009 \mathrm{E}-5 \mathrm{~m}^{4}$

$\mathrm{L} 1 \mathrm{~m}$

The solution steps taken considering the above mentioned data are as follows. With the help of equation;

$$
\begin{aligned}
& \mathrm{k}=\frac{12 * 1.2 \mathrm{E} 8 * 2.009 \mathrm{E}-5}{1^{3}}=50626.8 \mathrm{kN} / \mathrm{m} \\
& \omega=\sqrt{\frac{50626.8}{0.02460756224}}=1434.352658 \mathrm{rad} / \mathrm{s} \\
& \mathrm{f}_{\mathrm{m} 1}=\frac{1434.352658}{2 \pi}=228.2843157 \mathrm{~Hz}
\end{aligned}
$$

frequency value was obtained (Eq. 18). When the obtained data were evaluated, the scale factor of the column;

$$
\frac{f_{m 1}}{f_{p}}=\frac{228.2843157}{114.1350441}=2.0000
$$

was obtained Eq. (19).

1/4 Scaled Model Data of the Column

Dimensions $1001002 \mathrm{~mm}$

$\mathrm{E} 2.1 \mathrm{E} 8 \mathrm{KN} / \mathrm{m}^{2}$

I $1.255 \mathrm{E}-6 \mathrm{~m}^{4}$

L $0.5 \mathrm{~m}$

The solution steps taken considering the above mentioned data are as follows. With the help of Eq. (1);

$$
\begin{aligned}
& \mathrm{k}=\frac{12 * 1.2 \mathrm{E} 8 * 1.255 \mathrm{E}-6}{0.5^{3}}=25300.8 \mathrm{kN} / \mathrm{m} \\
& \omega=\sqrt{\frac{25300.8}{0.00307594528}}=2867.991264 \mathrm{rad} / \mathrm{s} \\
& \mathrm{f}_{\mathrm{m} 2}=\frac{2867.991264}{2 \pi}=456.4549865 \mathrm{~Hz}
\end{aligned}
$$

frequency value was obtained (Eq. 20). When the obtained data were evaluated, the scale factor of the column;

$$
\frac{\mathrm{f}_{\mathrm{m} 2}}{\mathrm{f}_{\mathrm{p}}}=\frac{456.4549865}{114.1350441}=4.0000
$$


was obtained Eq. (21).

The steps of calculation of the displacement values obtained as a result of considering the prototype, 1/2 and 1/4 scaled model of the cantilever beam that is box profile are presented as follows:

\section{The prototype Data of the Cantilever Beam}

Dimensions $400 \times 400 \times 8 \mathrm{~mm}, 2 \mathrm{~m}$

Modulus of Elasticity $\mathrm{E}=2.1 \mathrm{E} 8 \mathrm{KN} / \mathrm{m}^{2}$

System displacement $\delta=\frac{\mathrm{PL}^{3}}{3 \mathrm{EI}}$

$$
\left.\begin{array}{ll}
\text { System Weight }(\mathrm{P}) & \mathrm{P}=1.931201877 \mathrm{kN} \\
\text { Moment of Inertia } & \mathrm{I}=3.214 \mathrm{E}-4 \mathrm{~m}^{4}
\end{array}\right\} \text { TTable } \mathrm{Qu}
$$

The solution steps taken considering the above mentioned data are as follows. With the help of displacement equation for cantilever beam;

$$
\begin{aligned}
& \delta_{\mathrm{p}}=\frac{\mathrm{PL}^{3}}{3 \mathrm{EI}} \\
& \delta_{\mathrm{p}}=\frac{1.931201877 * 2^{3}}{3 * 2.1 \mathrm{E} 8 * 3.214 \mathrm{E}-4}=0.00007630 \mathrm{~m} \\
& \delta_{\mathrm{p}}=0.07630 \mathrm{~mm}
\end{aligned}
$$

was obtained displacement value which is given in Eq. (22). P load according to bulk mass acceptance is applied as system weight.

\section{1/2 Scaled Model Data of Cantilever Beam}

Dimensions $200 \times 200 \times 4 \mathrm{~mm}, 1 \mathrm{~m}$

Modulus of Elasticity $\mathrm{E}=2.1 \mathrm{E} 8 \mathrm{KN} / \mathrm{m}^{2}$

$$
\left.\begin{array}{ll}
\text { System displacement } & \delta=\frac{\mathrm{PL}^{3}}{3 \mathrm{EI}} \\
\text { System Weight }(\mathrm{P}) & \mathrm{P}=0.2414001856 \mathrm{kN} \\
\text { Moment of Inertia } & \mathrm{I}=2.009 \mathrm{E}-5 \mathrm{~m}^{4}
\end{array}\right\} \square \text { Table } \square \mathrm{Q}
$$

The solution steps taken considering the above mentioned data are as follows. With the help of displacement equation for cantilever beam;

$$
\begin{aligned}
& \delta_{\mathrm{m}}=\frac{\mathrm{PL}^{3}}{3 \mathrm{EI}} \\
& \delta_{\mathrm{m}}=\frac{0.2414001856 * 1^{3}}{3 * 2.1 \mathrm{E} 8 * 2.009 \mathrm{E}-5}=0.0000190729 \mathrm{~m} \\
& \delta_{\mathrm{m}}=0.0190729 \mathrm{~mm}
\end{aligned}
$$

displacement value is obtained (Eq. 23). P load according to bulk mass acceptance is applied as system weight. When the obtained data are evaluated, the scaled factor of the cantilever beam;

$$
\frac{\delta_{\mathrm{m}}}{\delta_{\mathrm{p}}}=\frac{0.0190729}{0.0763012}=0.249969
$$

was obtained (Eq. 24). The displacement values of the other systems are presented in next chapter. 


\subsection{Comparison of Results Obtained}

The frequency values of the all bearing systems are presented in detail in Tables 5, 6, 7 and $\mathbf{8}$ for different scaling types of the results of finite element analysis and mathematical formula.

Table 5. The frequency values obtained from the analytical and finite element analysis belonging to the box profile bearing systems for $1 / 2$ scaled.

\begin{tabular}{|c|c|c|c|c|c|c|c|}
\hline \multicolumn{8}{|c|}{ Box Profile } \\
\hline \multirow[b]{2}{*}{$\begin{array}{l}\text { Scale } \\
\text { Types }\end{array}$} & \multirow[b]{2}{*}{$\begin{array}{l}\text { Bearing System } \\
\text { Elements }\end{array}$} & \multicolumn{3}{|c|}{ Finite Element Analysis Results (Hz) } & \multicolumn{3}{|c|}{ Analytical Results (Hz) } \\
\hline & & Prototype & 1/2 Scaled Model & $\frac{f_{m}}{f_{p}}$ & Prototype & 1/2 Scaled Model & $\frac{f_{m}}{f_{p}}$ \\
\hline \multirow{2}{*}{ Geometric } & Column & 107.8369 & 76.2516 & 0.7071 & 114.1350 & 80.7107 & 0.7072 \\
\hline & Beam & 54.4533 & 38.5043 & 0.7071 & 57.0675 & 40.3553 & 0.7072 \\
\hline \multirow{2}{*}{$\begin{array}{l}\text { Geometric } \\
\text { and Mass }\end{array}$} & Column & 107.8369 & 215.6722 & 2.0000 & 114.1350 & 228.2843 & 2.0000 \\
\hline & Beam & 54.4533 & 108.9067 & 2.0000 & 57.0675 & 114.1422 & 2.0000 \\
\hline
\end{tabular}

Table 6. The frequency values obtained from the analytical and finite element analysis belonging to the box profile bearing systems for $1 / 4$ scaled.

\begin{tabular}{|c|c|c|c|c|c|c|c|}
\hline \multicolumn{8}{|c|}{ Box Profile } \\
\hline \multirow[b]{2}{*}{$\begin{array}{l}\text { Scale } \\
\text { Types }\end{array}$} & \multirow[b]{2}{*}{$\begin{array}{c}\text { Bearing System } \\
\text { Elements }\end{array}$} & \multicolumn{3}{|c|}{ Finite Element Analysis Results (Hz) } & \multicolumn{3}{|c|}{ Analytical Results (Hz) } \\
\hline & & Prototype & 1/4 Scaled Model & $\frac{\mathrm{f}_{\mathrm{m}}}{\mathrm{f}_{\mathrm{p}}}$ & Prototype & 1/4 Scaled Model & $\frac{f_{m}}{f_{p}}$ \\
\hline \multirow{2}{*}{ Geometric } & Column & 107.8369 & 53.9164 & 0.5000 & 114.1350 & 57.0569 & 0.5000 \\
\hline & Beam & 54.4533 & 27.2267 & 0.5000 & 57.0675 & 28.5284 & 0.5000 \\
\hline \multirow{2}{*}{$\begin{array}{l}\text { Geometric } \\
\text { and Mass }\end{array}$} & Column & 107.8369 & 431.3316 & 4.0000 & 114.1350 & 456.4550 & 4.0000 \\
\hline & Beam & 54.4533 & 217.8134 & 4.0000 & 57.0675 & 228.2275 & 4.0000 \\
\hline
\end{tabular}

Table 7. The frequency values obtained from the analytical and finite element analysis belonging to the I profile bearing systems for $1 / 2$ scaled.

\begin{tabular}{|c|c|c|c|c|c|c|c|c|}
\hline \multicolumn{9}{|c|}{ I Profile } \\
\hline \multirow[b]{2}{*}{$\begin{array}{l}\text { Scale } \\
\text { Types }\end{array}$} & \multirow[b]{2}{*}{$\begin{array}{l}\text { Bearing System } \\
\text { Elements }\end{array}$} & & \multicolumn{3}{|c|}{ Finite Element Analysis Results $(\mathrm{Hz})$} & \multicolumn{3}{|c|}{ Analytical Results (Hz) } \\
\hline & & & Prototype & 1/2 Scaled Model & $\frac{f_{m}}{f_{p}}$ & Prototype & 1/2 Scaled Model & $\frac{f_{m}}{f_{p}}$ \\
\hline \multirow{4}{*}{ Geometric } & \multirow{2}{*}{ Column } & $\mathrm{f} 1$ & 28.4324 & 26.3891 & 0.9281 & 28.1676 & 26.1506 & 0.9284 \\
\hline & & $\mathrm{f} 2$ & 109.0094 & 89.1932 & 0.8182 & 117.9994 & 96.7328 & 0.8198 \\
\hline & \multirow{2}{*}{ Beam } & $\mathrm{f1}$ & 14.0369 & 13.0223 & 0.9277 & 14.0838 & 13.0753 & 0.9284 \\
\hline & & $\mathrm{f} 2$ & 55.4655 & 45.3849 & 0.8183 & 58.9997 & 48.3664 & 0.8198 \\
\hline \multirow{4}{*}{$\begin{array}{l}\text { Geometric } \\
\text { and Mass }\end{array}$} & \multirow{2}{*}{ Column } & f1 & 28.4324 & 64.2054 & 2.2582 & 28.1676 & 63.6252 & 2.2588 \\
\hline & & $\mathrm{f} 2$ & 109.0094 & 217.0099 & 1.9907 & 117.9994 & 235.3539 & 1.9945 \\
\hline & \multirow{2}{*}{ Beam } & f1 & 14.0369 & 31.6836 & 2.2572 & 14.0838 & 31.8126 & 2.2588 \\
\hline & & $\mathrm{f} 2$ & 55.4655 & 110.4228 & 1.9908 & 58.9997 & 117.6770 & 1.9945 \\
\hline
\end{tabular}

Table 8. The frequency values obtained from the analytical and finite element analysis belonging to the I profile bearing systems for $1 / 4$ scaled.

\begin{tabular}{|c|c|c|c|c|c|c|c|c|}
\hline \multicolumn{10}{|c|}{ I Profile } \\
\hline \multirow{3}{*}{$\begin{array}{c}\text { Scale } \\
\text { Types }\end{array}$} & $\begin{array}{c}\text { Bearing System } \\
\text { Elements }\end{array}$ & $\frac{\mathrm{f}_{\mathrm{m}}}{\mathrm{f}_{\mathrm{p}}}$ & Prototype & $\mathbf{1} / 4$ Scaled Model & $\frac{\mathrm{f}_{\mathrm{m}}}{\mathrm{f}_{\mathrm{p}}}$ & Prototype & 1/4 Scaled Model & \multicolumn{3}{|c|}{ Analytical Results (Hz) } \\
\hline
\end{tabular}


(Table 8) contd.....

\begin{tabular}{|c|c|c|c|c|c|c|c|c|}
\hline \multicolumn{9}{|c|}{ I Profile } \\
\hline \multirow[b]{2}{*}{$\begin{array}{l}\text { Scale } \\
\text { Types }\end{array}$} & \multirow[b]{2}{*}{$\begin{array}{c}\text { Bearing System } \\
\text { Elements }\end{array}$} & \multirow{2}{*}{$\frac{f_{m}}{f_{p}}$} & \multicolumn{3}{|c|}{ Finite Element Analysis Results (Hz) } & \multicolumn{3}{|c|}{ Analytical Results (Hz) } \\
\hline & & & Prototype & 1/4 Scaled Model & $\frac{f_{m}}{f_{p}}$ & Prototype & 1/4 Scaled Model & \\
\hline \multirow{4}{*}{ Geometric } & \multirow{2}{*}{ Column } & $\mathrm{f} 1$ & 28.4324 & 24.9502 & 0.8775 & 28.1676 & 24.7503 & 0.8787 \\
\hline & & $\mathrm{f} 2$ & 109.0094 & 75.1150 & 0.6891 & 117.9994 & 81.1671 & 0.6879 \\
\hline & \multirow{2}{*}{ Beam } & $\mathrm{fl}$ & 14.0369 & 12.3147 & 0.8773 & 14.0838 & 12.3752 & 0.8787 \\
\hline & & $\mathrm{f} 2$ & 55.4655 & 38.1692 & 0.6881 & 58.9997 & 40.5835 & 0.6879 \\
\hline \multirow{4}{*}{$\begin{array}{l}\text { Geometric } \\
\text { and Mass }\end{array}$} & \multirow{2}{*}{ Column } & $\mathrm{fl}$ & 28.4324 & 142.7637 & 5.0212 & 28.1676 & 141.6201 & 5.0277 \\
\hline & & $\mathrm{f} 2$ & 109.0094 & 429.8042 & 3.9428 & 117.9994 & 464.4345 & 3.9359 \\
\hline & \multirow{2}{*}{ Beam } & f1 & 14.0369 & 70.4643 & 5.0190 & 14.0838 & 70.8101 & 5.0277 \\
\hline & & $\mathrm{f} 2$ & 55.4655 & 218.4021 & 3.9376 & 58.9997 & 232.2176 & 3.9359 \\
\hline
\end{tabular}

As can be seen from the results, the scale factors $\left(f_{m} / f_{p}\right)$ between different systems with the same scale are constant.

The displacement values of the other bearing systems are presented in detail in Tables 9, 10, Table 11 and 12 for different scaling types of the results of finite element analysis and mathematical formula. As can be seen from the results, the scale factor $\left(\delta_{\mathrm{m}} \delta_{\mathrm{p}}\right)$ between different systems with the same scale is constant.

Table 9. The displacement values obtained from the analytical and finite element analysis belonging to the box profile bearing systems for $1 / 2$ scaled.

\begin{tabular}{|c|c|c|c|c|c|c|c|}
\hline \multicolumn{8}{|c|}{ Box Profile } \\
\hline \multirow[b]{2}{*}{$\begin{array}{l}\text { Scale } \\
\text { Types }\end{array}$} & \multirow[b]{2}{*}{$\begin{array}{c}\text { Bearing System } \\
\text { Elements }\end{array}$} & \multicolumn{3}{|c|}{ Finite Element Analysis Results (mm) } & \multicolumn{3}{|c|}{ Analytical Results (mm) } \\
\hline & & Prototype & 1/2 Scaled Model & $\frac{\delta_{\mathrm{m}}}{\delta_{\mathrm{p}}}$ & Prototype & 1/2 Scaled Model & $\frac{\delta_{\mathrm{m}}}{\delta_{\mathrm{p}}}$ \\
\hline \multirow{2}{*}{ Geometric } & Column & 0.00073 & 0.00147 & 2.0003 & 0.0007357 & 0.001466 & 2.0000 \\
\hline & Beam & 0.08377 & 0.16750 & 2.0000 & 0.0763 & 0.1526 & 2.0000 \\
\hline \multirow{2}{*}{$\begin{array}{l}\text { Geometric } \\
\text { and Mass }\end{array}$} & Column & 0.00073 & 0.00018 & 0.2500 & 0.0007357 & 0.0001833 & 0.2492 \\
\hline & Beam & 0.08377 & 0.02094 & 0.2500 & 0.0763 & 0.0191 & 0.2500 \\
\hline
\end{tabular}

Table 10. The displacement values obtained from the analytical and finite element analysis belonging to the box profile bearing systems for $1 / 4$ scaled.

\begin{tabular}{|c|c|c|c|c|c|c|c|}
\hline \multicolumn{9}{|c|}{ Box Profile } \\
\hline \multirow{2}{*}{$\begin{array}{c}\text { Scale } \\
\text { Types }\end{array}$} & $\begin{array}{c}\text { Bearing System } \\
\text { Elements }\end{array}$ & \multicolumn{2}{|c|}{ Finite Element Analysis Results (mm) } & \multicolumn{3}{c|}{ Analytical Results (mm) } \\
\cline { 4 - 9 } & & Prototype & $\mathbf{1 / 4}$ Scaled Model & $\frac{\delta_{\mathrm{m}}}{\delta_{\mathrm{p}}}$ & Prototype & \multicolumn{1}{|c|}{$\mathbf{1 / 4}$ Scaled Model } & $\frac{\delta_{\mathrm{m}}}{\delta_{\mathrm{p}}}$ \\
\hline \multirow{2}{*}{ Geometric } & Column & 0.00073 & 0.00293 & 4.0000 & 0.0007357 & 0.002932 & 3.9853 \\
\cline { 2 - 9 } & Beam & 0.08377 & 0.3351 & 4.0000 & 0.0763 & 0.3053 & 4.0000 \\
\hline \multirow{2}{*}{$\begin{array}{c}\text { Geometric } \\
\text { and Mass }\end{array}$} & Column & 0.00073 & 0.0000458 & 0.0625 & 0.0007357 & 0.0000458 & 0.0623 \\
\cline { 2 - 9 } & Beam & 0.08377 & 0.00522 & 0.0624 & 0.0763 & 0.0048 & 0.0625 \\
\hline
\end{tabular}

Table 11. The displacement values obtained from the analytical and finite element analysis belonging to the I profile bearing systems for $1 / 2$ scaled.

\begin{tabular}{|c|c|c|c|c|c|c|c|}
\hline \multicolumn{9}{|c|}{ I Profile } \\
\hline \multirow{2}{*}{$\begin{array}{c}\text { Scale } \\
\text { Types }\end{array}$} & \multirow{2}{*}{$\begin{array}{c}\text { Bearing System } \\
\text { Elements }\end{array}$} & \multicolumn{2}{|c|}{ Finite Element Analysis Results (mm) } & \multicolumn{3}{c|}{ Analytical Results (mm) } \\
\cline { 4 - 9 } & & Prototype & $\mathbf{1 / 2}$ Scaled Model & $\frac{\delta_{\mathrm{m}}}{\delta_{\mathrm{p}}}$ & \multirow{2}{*}{ Prototype } & \multicolumn{1}{|c|}{$\mathbf{1 / 2}$ Scaled Model } & $\frac{\delta_{\mathrm{m}}}{\delta_{\mathrm{p}}}$ \\
\hline \multirow{2}{*}{ Geometric } & Column & 0.00073 & 0.00109 & 1.4794 & 0.000733 & 0.001086 & 1.4816 \\
\cline { 2 - 9 } & Beam & 0.08377 & 0.1206 & 1.4935 & 0.07138 & 0.10622 & 1.4880 \\
\hline \multirow{2}{*}{$\begin{array}{c}\text { Geometric } \\
\text { and Mass }\end{array}$} & Column & 0.00073 & 0.00018 & 0.2501 & 0.000733 & 0.000184 & 0.2510 \\
\cline { 2 - 9 } & Beam & 0.08377 & 0.02037 & 0.2432 & 0.07138 & 0.01794 & 0.2514 \\
\hline
\end{tabular}




\subsection{Application of Formulas Obtained by Formed Similarity}

Calculation of the frequency value of the $1 / 2$ scaled model by using the frequency value of the prototype box cantilever beam is as follows. If written, $\mathrm{I}_{\mathrm{p}}=3.214 \mathrm{E}-4 \mathrm{~m}^{4}, \mathrm{I}_{\mathrm{m}}=2.009 \mathrm{E}-5 \mathrm{~m}^{4}$ (Table 4) and $\mathrm{f}_{\mathrm{p}}=107,8369 \mathrm{hz}$ Table 5 in Eq. (6),

$$
\begin{aligned}
& \mathrm{f}_{\mathrm{m}}=\sqrt{\frac{\mathrm{I}_{\mathrm{m}}}{\mathrm{I}_{\mathrm{p}}}} \sqrt{\left(\frac{\mathrm{L}_{\mathrm{p}}}{\mathrm{L}_{\mathrm{m}}}\right)^{3}} \mathrm{f}_{\mathrm{p}} \\
& \mathrm{f}_{\mathrm{m}}=\sqrt{\frac{2.009 \mathrm{E}-5}{3.214 \mathrm{E}-4}} \sqrt{\left(\frac{2}{1}\right)^{3}} 107.8369 \\
& \mathrm{f}_{\mathrm{m}}=38.506693 \mathrm{~Hz}
\end{aligned}
$$

Eq. (25) is obtained. This result obtained with Eq. (25) agrees with the $1 / 2$ geometric scaled (constant mass) result presented for the box cantilever beam in Table $\mathbf{5}$.

Table 12. The displacement values obtained from the analytical and finite element analysis belonging to the I profile bearing systems for $1 / 4$ scaled.

\begin{tabular}{|c|c|c|c|c|c|c|c|}
\hline \multicolumn{2}{|c|}{ I Profile } \\
\hline \multirow{2}{*}{$\begin{array}{c}\text { Scale } \\
\text { Types }\end{array}$} & \multirow{2}{*}{$\begin{array}{c}\text { Bearing System } \\
\text { Elements }\end{array}$} & \multicolumn{2}{|c|}{ Finite Element Analysis Results (mm) } & \multicolumn{3}{c|}{ Analytical Results (mm) } \\
\cline { 3 - 9 } & & Prototype & $\mathbf{1 / 4}$ Scaled Model & $\frac{\delta_{\mathrm{m}}}{\delta_{\mathrm{p}}}$ & Prototype & $\mathbf{1 / 4}$ Scaled Model & $\frac{\delta_{\mathrm{m}}}{\delta_{\mathrm{p}}}$ \\
\hline \multirow{2}{*}{ Geometric } & Column & 0.00073 & 0.001501 & 2.0466 & 0.000733 & 0.001503 & 2.0505 \\
\cline { 2 - 9 } & Beam & 0.08377 & 0.170500 & 2.0353 & 0.07139 & 0.1509 & 2.1135 \\
\hline \multirow{2}{*}{$\begin{array}{c}\text { Geometric } \\
\text { and Mass }\end{array}$} & Column & 0.00073 & 0.000046 & 0.0625 & 0.000733 & 0.000459 & 0.0626 \\
\cline { 2 - 9 } & Beam & 0.08377 & 0.005208 & 0.0622 & 0.07139 & 0.0046 & 0.0646 \\
\hline
\end{tabular}

Calculation of the displacement value of the $1 / 2$ scaled model by using the displacement value of the prototype box cantilever beam is as follows. If written $\mathrm{I}_{\mathrm{p}}=3.214 \mathrm{E}-4 \mathrm{~m}^{4}, \mathrm{I}_{\mathrm{m}}=2.0009 \mathrm{E}-5 \mathrm{~m}^{4}$ Table 4 and ${ }_{\mathrm{p}}=0.08377 \mathrm{~mm}$ Table 8 in Eq. (12);

$$
\begin{aligned}
\frac{\delta_{p}}{\delta_{m}} & =\frac{I_{m}}{I_{p}} S^{3} \\
\delta_{m} & =\frac{I_{p}}{I_{m}} \frac{1}{S^{3}} \delta_{p} \\
\delta_{m} & =\frac{3.214 E-4}{2.009 E-5} \frac{1}{2^{3}} 0.08377 \\
\delta_{m} & =0.167519 m m
\end{aligned}
$$

Eq. (26) is obtained. This result obtained with Eq. (26) agrees with the $1 / 2$ geometric scaled (constant mass) result presented for the box cantilever beam in Table $\mathbf{8}$.

\section{Effect of Scale Change on Influence Diagrams}

The influence diagrams under the weight of the system at the column and cantilever beam are examined in Figs. (3-4). The relationship between the prototype and model with the field equations used to obtain the section effects was observed. The influence diagrams of the finite element models were examined and the existence of the relationship was determined. 


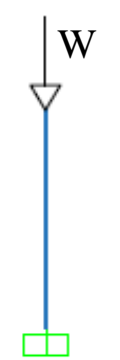

a) Loading status

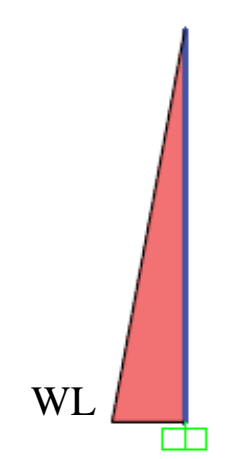

b) Shear force

Fig. (3). Loading status and axial force for column.

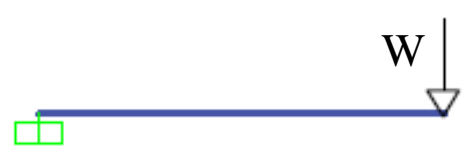

a) Loading status

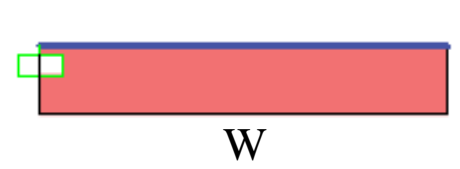

b) Shear force

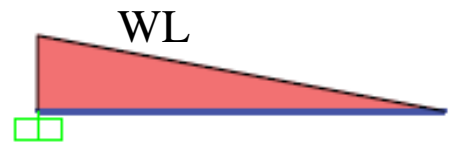

c) Bending moment

Fig. (4). Loading status, shear force and bending moment for cantilever beam.

The parameters affecting axial force are system weight and column dimensions change.

The parameters affecting shear force and bending moment are system weight and beam length change.

The influence diagrams obtained from the finite element analysis are presented comparatively in Figs. (5, 6, 7 and 8).
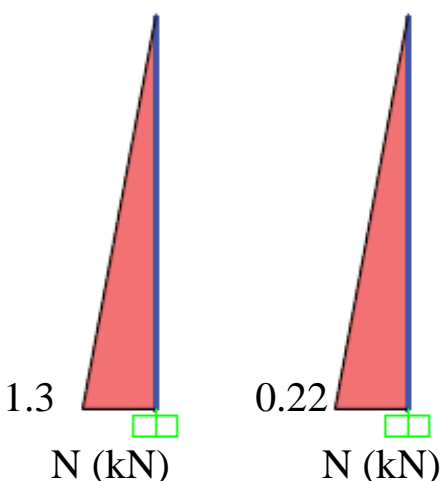

0.04

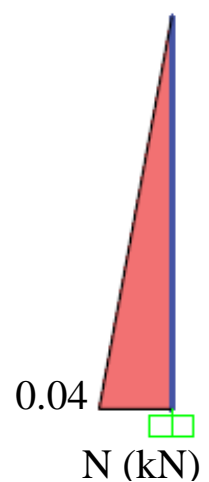

Prototype
$1 / 2$ Scaled

1/4 Scale

a) I profile
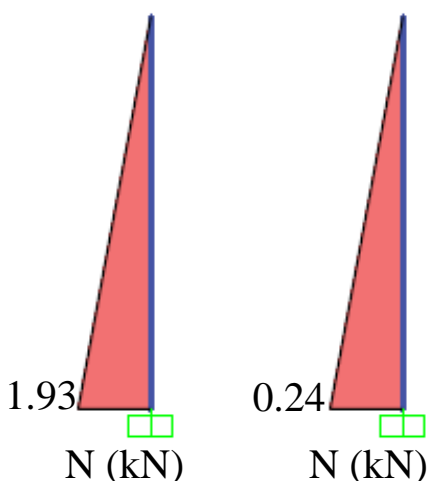

0.03

$\mathrm{N}(\mathrm{kN})$

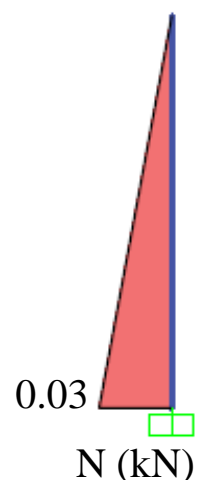

Prototype

1/2 Scaled

1/4 Scaled

b) Box profile

Fig. (5). Axial force diagram for geometric scale (variable mass). 

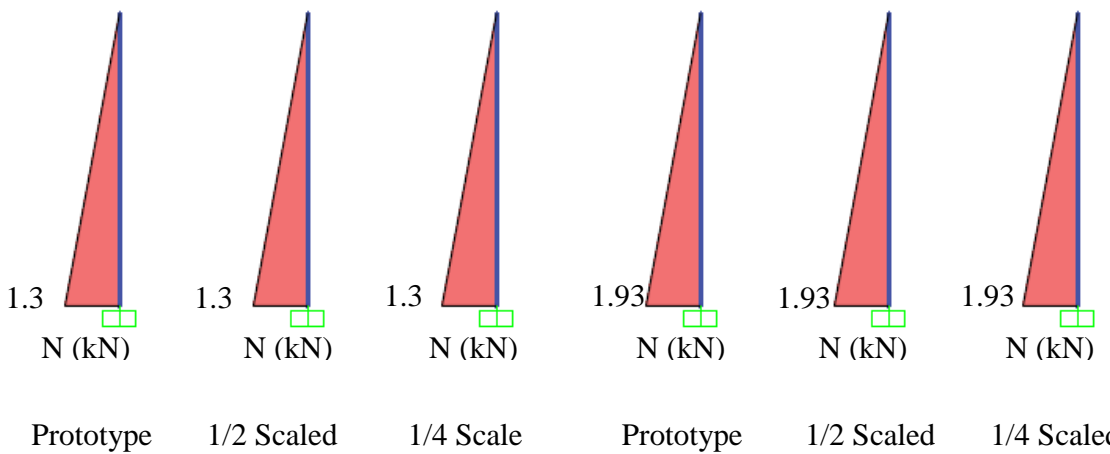

a) I profile

1/2 Scaled $1 / 4$ Scaled

b) Box profile

Fig. (6). Axial force diagram for geometric scale (constant mass).
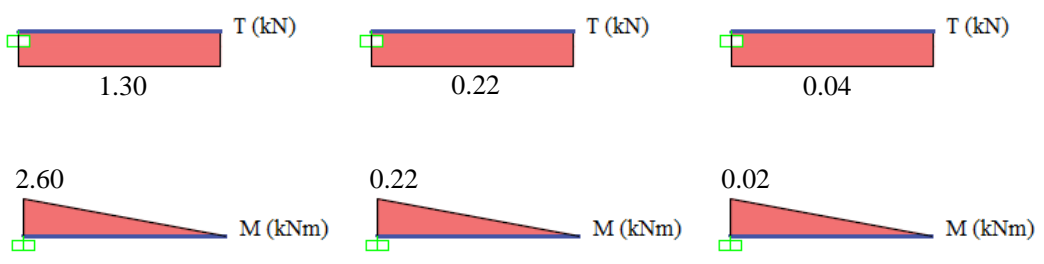

Prototype

$1 / 2$ Scaled

1/4 Scale

a) I profile
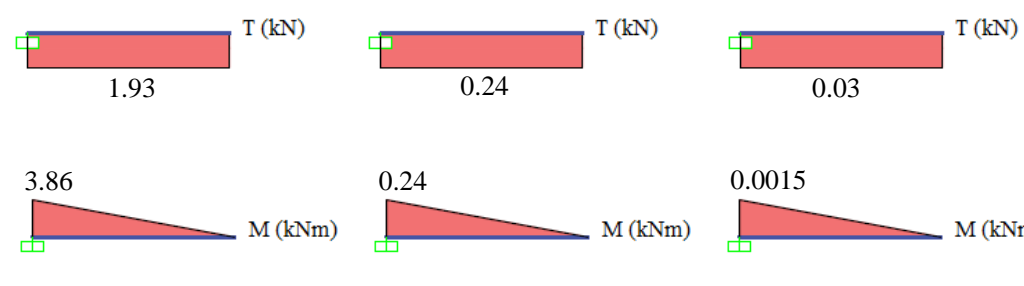

0.0015

Prototype

1/2 Scaled

1/4 Scale

b) Box profile

Fig. (7). Influence diagram for geometric scale (variable mass).
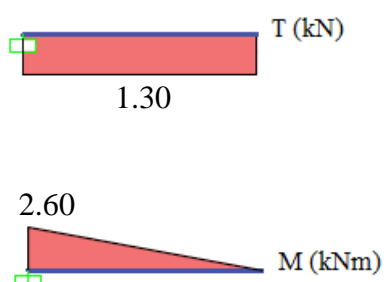

Prototype
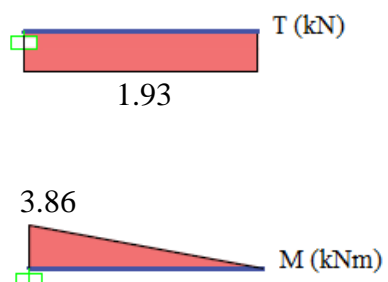

Prototype

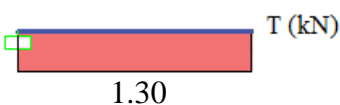

1.30

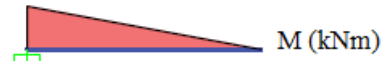

$1 / 2$ Scaled

a) I profile

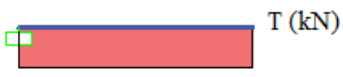

1.93

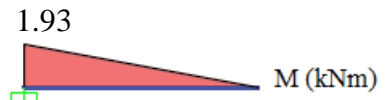

1/2 Scaled

b) Box profile

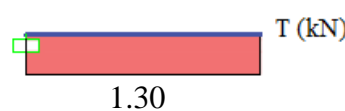

0.65

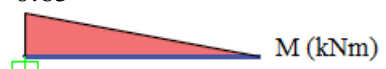

1/4 Scale

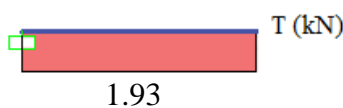

0.965

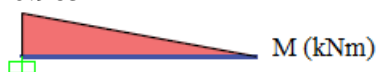

1/4 Scale

Fig. (8). Influence diagram for geometric scale (constant mass). 
When the diagrams were examined, it was observed that changes were due to the scale type and scale ratio between the prototype and the model.

\section{CONCLUSION}

This study aimed to determine the characteristics properties and structural behaviors of steel bearing systems by establishing similarity relationship between prototype and scaled models. Column and cantilever beams were selected for application of the scale effect in steel bearing systems. The dimensions in the steel tables were selected and processed. In the studies carried out on box and I profiles, 1/2 and 1/4 scaled models were used. The finite element models of the selected profiles are created with the Sap2000 [18] program. Frequency and displacement values were obtained analytically by using mathematical models of systems. The frequency values of the all bearing systems are presented in detail for different scaling types of the results of finite element analysis and mathematical formula. As can be seen from the results, the scale factors (and) between different systems with the same scale are constant. Also, the influence diagrams obtained from the finite element analysis for different scaling types are presented comparatively. When the diagrams were examined, it was observed that changes were due to the scale type and scale ratio between the prototype and the model. For example, shear force is constant in geometric scale for box cantilever beam and bending moment changed with the changing of beam span. It was observed in this study that the characteristic properties and structural behaviors of the systems can be obtained establishing a similarity relation, by establishing small scaled models.

\section{CONSENT FOR PUBLICATION}

Not applicable.

\section{CONFLICT OF INTEREST}

The authors declare no conflict of interest, financial or otherwise.

\section{ACKNOWLEDGEMENTS}

Declared none..

\section{REFERENCES}

[1] J. Zhou, G. Lin, T. Zhu, A.D. Jefferson, and F.W. Williams, "Experimental investigation into seismic failure of high arch dams", J. Struct. Eng., vol. 126, pp. 926-935, 2000.

[http://dx.doi.org/10.1061/(ASCE)0733-9445(2000)126:8(926)]

[2] D. Jiang, and D.W. Shu, "Prediction of peak acceleration of one degree of freedom structures by scaling law", J. Struct. Eng., vol. 131, no. 4, pp. 582-588, 2005. [http://dx.doi.org/10.1061/(ASCE)0733-9445(2005)131:4(582)]

[3] S. Oliveira, and R. Faria, "Numerical simulation of collapse scenarios in reduced scale tests of arch dams", Eng. Struct., vol. 28, pp. 1430-1439, 2006

[http://dx.doi.org/10.1016/j.engstruct.2006.01.012]

[4] H. Wang, and D. Li, "Experimental study of dynamic damage of an arch dam", Earthquake Eng. Struct. Dynam., vol. 36, pp. 347-366, 2006. [http://dx.doi.org/10.1002/eqe.637]

[5] B.S. Wang, and Z.C. He, "Crack detection of arch dam using statistical neural network based on the reductions of natural frequencies", J. Sound Vibrat., vol. 302, pp. 1037-1047, 2007.

[http://dx.doi.org/10.1016/j.jsv.2007.01.008]

[6] H. Wang, and D. Li, "Experimental study of seismic overloading of large arch dam", Earthquake Eng. Struct. Dynam., vol. 35, pp. 199-216, 2005 .

[http://dx.doi.org/10.1002/eqe.517]

[7] M. Ramu, V. Prabhu Raja, and P. R. Thyla, "Establishment of structural similitude for elastic models and validation of scaling laws", KSCE J. Civ. Eng., vol. 17, no. 1, pp. 139-144, 2013. [http://dx.doi.org/10.1007/s12205-013-1216-x]

[8] P.L. Datin, and D.O. Prevatt, "Using instrumented small-scale models to study structural load paths in wood-framed buildings", Eng. Struct., vol. 54, pp. 47-56, 2013.

[http://dx.doi.org/10.1016/j.engstruct.2013.03.039]

[9] F. Hafeez, and F. Almaskari, "Experimental investigation of the scaling laws in laterally indented filament wound tubes supported with v shaped cradles", Compos. Struct., vol. 126, pp. 265-284, 2015.

[http://dx.doi.org/10.1016/j.compstruct.2015.02.073] 
[10] X. Lu, B. Zhou, and W. Lu, "Shaking table test and numerical analysis of a high-rise building with steel reinforced concrete column and reinforce concrete core tube", Struct. Des. Tall Spec. Build., vol. 24, pp. 1019-1038, 2015. [http://dx.doi.org/10.1002/tal.1224]

[11] M. Shehadeh, Y. Shennawy, and H. El-Gamal, "Similitude and scaling of large structural elements: Case study", Alexandria Engineering Journal, vol. 54, pp. 147-154, 2015. [http://dx.doi.org/10.1016/j.aej.2015.01.005]

[12] A. Carpinteri, and M. Corrado, "Dimensional analysis approach to the plastic rotation capacity of over-reinforced concrete beams", Eng. Fract. Mech., vol. 77, pp. 1091-1100, 2010.

[http://dx.doi.org/10.1016/j.engfracmech.2010.02.021]

[13] M. Ramu, R.V. Prabhu, and P. Thyla, "Development of structural similitude and scaling laws for elastic models", http://www.fvt.tuke.sk/journal/pdf10/ 3-str-67-69.pdf

[14] P. Balaguer, and J.A. Claramonte, "Characterization and control of dimensionally similar systems", J. Franklin Inst., vol. 348, pp. 1814-1831, 2011.

[http://dx.doi.org/10.1016/j.jfranklin.2011.05.005]

[15] A. Ghosh, "Scaling laws", Mechanics Over Micro and Nano Scales, May 2011. [http://dx.doi.org/10.1007/978-1-4419-9601-5_2]

[16] S. Balawi, O. Shahid, and M.A. Mulla, "Similitude and scaling laws-static and dynamic behaviour beams and plates", Procedia Eng., vol. 114 , pp. 330-337, 2015 [http://dx.doi.org/10.1016/j.proeng.2015.08.076]

[17] URL-1, http://dubazlar.com/yahoo_site_admin/assets/docs/PROHES.12180103.PNG 12. 09. 2017

[18] SAP2000, Integrated Finite Element Analysis and Design of Structures., Computers and Structures, Inc.: Berkeley, California, USA, 2016.

(C) 2018 Altunışık et al.

This is an open access article distributed under the terms of the Creative Commons Attribution 4.0 International Public License (CC-BY 4.0), a copy of which is available at: (https://creativecommons.org/licenses/by/4.0/legalcode). This license permits unrestricted use, distribution, and reproduction in any medium, provided the original author and source are credited. 